\title{
A coherent approach to the thermophysical properties of mixtures: hard work and software
}

\author{
W.A. Wakeham \\ IUPAC Project Centres for Thermodynamic Tables and Transport Properties, Department \\ of Chemical Engineering, Imperial College, London SW7 2BY, U.K.
}

\begin{abstract}
The paper describes extensions of the work of the IUPAC Project Centres for Thermodynamic Tables and Transport Properties at Imperial College, London, to mixtures of fluids. The extension has been conducted in such a way as to make maximum use of the accurate representations of the properties of pure components developed over twenty-five years. A number of results are provided as illustrations of the benefit of this approach for a range of systems for which high accuracy in the prediction of mixture properties is important.
\end{abstract}

\section{INTRODUCTION}

The IUPAC Project for Thermodynamic Tables was initiated in 1965 under the auspices of IUPAC Commission I.2. Its purpose was to evaluate critically the available experimental information on the properties of pure fluids and to produce internationally-acceptable tables of these properties for use in science and industry. The initiation of the project and, subsequently, of the Project Centre at Imperial College in London provided a focus for the activities of a number of groups around the world and, more importantly, a platform for the conduct of the argument about importance of such work on an international scale. Professor D.M. Newitt, was the foremost proponent of the cause since he foresaw the need for accurate values of the properties of fluids to secure optimal designs of process plant and, owing to the increasing internationalisation of industry, the need for agreement among countries as to the values of properties used in design. Since the staff of the Project Centre and others were working in advance of the realisation by industry that these properties were required, these early days were difficult and have only been slightly ameliorated over the intervening twenty-five years. However, today, the Project Centre for Thermodynamic Tables at Imperial College continues in existence largely as a result of the unwavering support of Commission I.2 and the $U_{K}$ government through various agencies. The arguments for the cause have, however, been strengthened over the years by the advent of computer-aided design, the need for more accurate and 'quality-assured' thermophysical property data for design (for which the IUPAC Centre has achieved renown), the increasing extent of custody transfer of materials across national boundaries and the scale of international licensing and sale of process-plant designs.

The output of the Centre comprises twelve volumes in the series 'International Thermodynamic Tables of the Fluid State' $(e . g$. ref. 1 \& 2), which are widely-used in industry and science as the definitive statement of knowledge with respect to the properties of twelve pure fluids. Over the years the Centre's work has been supplemented by the friendly and valuable contribution of many workers from all over the world. Furthermore, the scope of its activities was broadened in 1983 by the creation of an IUPAC Subcomittee on Transport Properties of Fluids and a corresponding Project Centre. Nevertheless, throughout the duration of these projects, they have concentrated almost exclusively upon pure fluids, delving into the minefield of mixtures only to encompass the effects of impurities upon otherwise high-purity materials. This approach was often defended by Dr. Selby Angus on the grounds that there were many other groups concerned with the thermophysical properties of mixtures who required as input the properties of the pure components. However, time has revealed that whereas the first part of Angus' statement remains true, it has not been the case that these same groups have made use of the best possible representations of the properties of the pure components. Thus, the IUPAC-approved equations for the description of the properties of pure fluids have found rather greater application in industry than in science and have most certainly not fulfilled their potential with respect to the properties of mixtures.

Guided by this background, the Project Centres at Imperial College have formed the view that they must depart from their 'pure' ideal and enter the field of mixtures with a mission consistent with the overriding aim of IUPAC 'to standardise and codify in the field of 
thermodynamics'. Interpreted in the present context this means that, in addition to their traditional activitiy, the Project Centres now seek to utilize their accurate representations of the properties of pure fluids to describe the properties of a set of fluid mixtures where accuracy or quality-assurance is a primary requirement. It is naturally consistent with this objective that the treatment of such mixtures should make full use of the representations of the properties of pure components developed already and be based securely on as much statistical-mechanical theory as possible. This paper summarizes the methodology whereby this aim has been accomplished over the last few years and implemented in a further computer program that will shortly be available.

\section{THERMODYNAMIC PROPERTIES}

\section{Theory}

The most effective manner in which the accurate, but complex, equations of state developed by the IUPAC Centre for pure fluids can be applied to mixtures is through some form of corresponding states principle (ref. 3). The particular form of this principle most often adopted in our work is a 'two-fluid' model first proposed by Watson and Rowlinson (ref. 4). In this approach the basic working equation represents the configurational Helmholtz free energy of a mixture as

$$
A_{\text {mix }}(V, T, X)=N_{A} k T \sum_{i}^{N} x_{i} \ln x_{i}+\underset{i}{\sum} x_{i} A_{i}^{h}(V, T)
$$

where the first term on the right-hand side represents the ideal free energy change upon mixing and $A_{i}^{h}(V, T)$ is the configurational free energy of a hypothetical pure substance which represents component $i$ in the mixture of $N$ components. $A_{i}^{h}(V, T)$ is called the hypothetical or 'pseudo' pure substance property because it must represent not only the behaviour of pure substance $i$ but also account for the interaction of $i$ with all unlike species in the mixture.

In the corresponding states approach, $A_{i}^{h}(V, T)$ is obtained from some reference equation of state evaluated at scaled conditions

$$
A_{i}^{h}(V, T)=f_{i} A_{i}^{r e f}\left(V / h_{i}, T / f_{i}\right)
$$

where $\Lambda_{i}^{\text {ref }}$ denotes the free energy of particular reference substance for hypothetical component $i$ and $f_{i}$ and $h_{i}$ are the scaling parameters for temperature and volume. The hypothetical substance and its reference substance are assumed to obey a principle of corresponding states.

It is important to note, in the context of the work of the IUPAC Project Centres, that each pseudo-substance can be referred to a different, arbitrarily complex, reference equation of state. Thus, this procedure for the evaluation of the free-energy of a mixture seeks to find the properties of an appropriate number of pseudo-substances for the mixture whose properties may be combined according to equation (1) to determine the properties of the mixture. Thus, it differs from the approach based upon simpler (predominantly-cubic) equations of state (ref. 5). It is a natural expectation that the properties of pseudo-i in a mixture will most nearly be conformal with the properties of the real component $i$. Thus, by using the equation of state for the real component $i$ as the reference substance for pseudo-i it is reasonable to expect that any errors arising from a lack of conformality should be minimized.

The remaining barrier to the implementation of these principles concerns the identification of the characteristics of the pseudo-components $i$. A number of means of identification have been proposed (ref. $6 \& 7$ ). The one that we have adopted is that consistent with Rowlinson's original formulation of the problem and is known as the van der Waals' two-fluid model (ref. 8). Within this framework, the pseudo-component is characterised by just two scaling parameters $h_{i}$ and $f_{i}$ which, by the nature of the model adopted, must be related to scaling parameters $h_{i j}$ and $f_{i j}$ for each pairwise interaction in the fluid. The particular form of relationship must be established through statistical-mechanical arguments. The most common form is that given originally by Rowlinson (ref. $3 \& 4$ )

$$
h_{i}=\sum_{j} x_{j} h_{i j} \quad \text { and } \quad f_{i}=\sum_{j} x_{j} h_{i j} f_{i j} / h_{i}
$$


Because these relationships lie at the heart of the evaluation procedure, current work on mixtures in the Project Centre has been concentrated in this area (ref. 9).

The various cross-parameters $h_{i j}$ and $f_{i j}$ can be determined from an appropriate set of combining rules, such as those of Lorentz and Berthelot,

$$
h_{i j}=\eta_{i j}\left[\frac{\left(h_{i j}^{r}\right)^{1 / 3}}{2}+\frac{\left(h_{j j}^{r}\right)^{1 / 3}}{2}\right]^{3}
$$

and

$$
f_{i j}=\xi_{i j}\left[f_{i i}^{r} f_{j j}^{r}\right]^{\frac{1}{2}}
$$

Here the superscript $r$ refers to the reference substance used to describe the hypothetical component $i$ so that it may indeed indicate any real substances including real $i$. The parameters $\eta_{i j}$ and $\xi_{i j}$ are adjustable and may be used to compensate for deviations from the simple combining rules.

Finally, the pure component reduction parameters are themselves given by the expressions

$$
\mathrm{h}_{\mathrm{i} i}^{\mathrm{r}}=\left[\mathrm{V}_{\mathrm{ci}} / \mathrm{V}_{\mathrm{c}}^{\mathrm{r}}\right] \phi_{\mathrm{i}}^{\mathrm{r}}, \mathrm{f}_{\mathrm{ii}}^{\mathrm{r}}=\left[\mathrm{T}_{\mathrm{ci}} / \mathrm{T}_{\mathrm{c}}^{\mathrm{r}}\right] \theta_{\mathrm{i}}^{\mathrm{r}}
$$

The factors $\phi_{i}^{r}$ and $\theta_{i}^{r}$ are molecular shape factors which account for deviations from conformality between the pseudo-substance $i$ and the reference substance $r$ (ref. 10). Working equations for all of the thermodynamic properties for a mixture can be derived from these results, including the evaluation of the composition and densities of various phases in equilibrium at prescribed conditions of pressure and temperature, subject only to the construction of a well-designed algorithm (ref.11). Because the phase envelope has proved the most sensitive test of the worth of a predictive scheme, it is this behaviour that has been selected to illustrate the results of the work.

\section{THERMODYNAMIC RESULTS}

Figures 1 to 4 show comparisons of the predicted phase envelope with that determined experimentally for a number of systems for which equations of state promulgated or established by the IUPAC Centre are available.

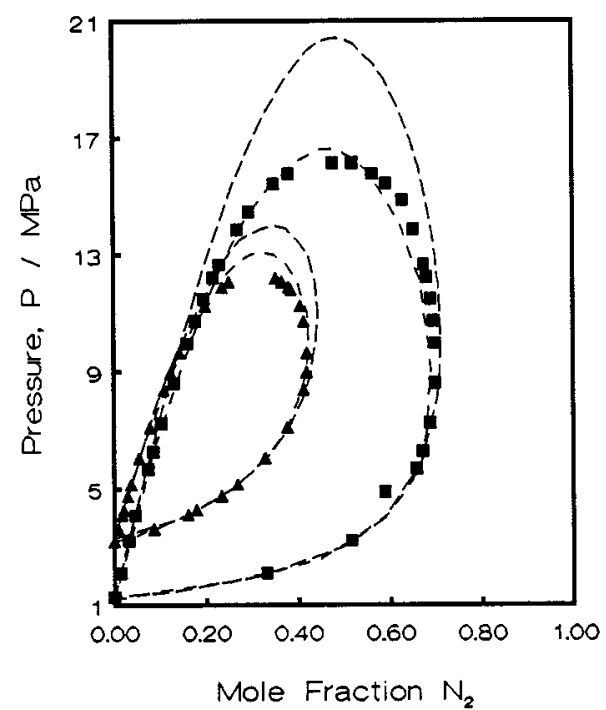

Fig. 1. Phase equilibria of $\mathrm{N}_{2}+\mathrm{CO}_{2}$. Experiment: $\triangle 270 \mathrm{~K} ; 240 \mathrm{~K}$.

Prediction: - - SRK; - - Present work.

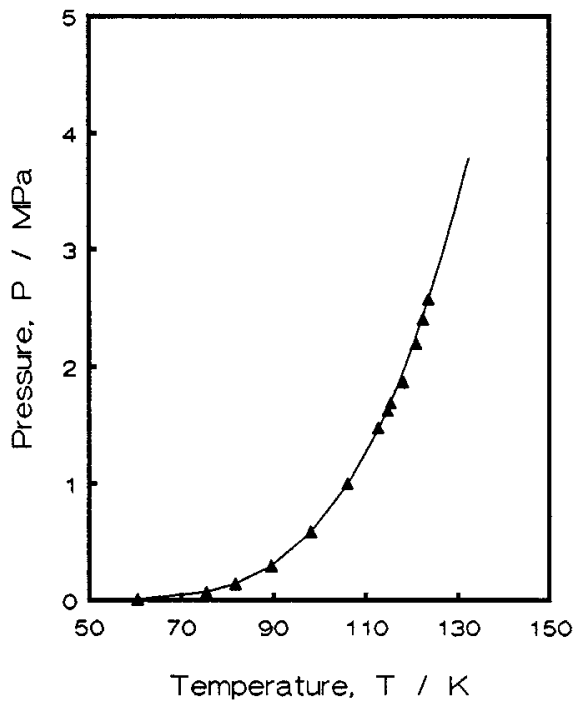

Fig. 2. Bubble point of air. experimental correlation. $\Delta$ predictions. 


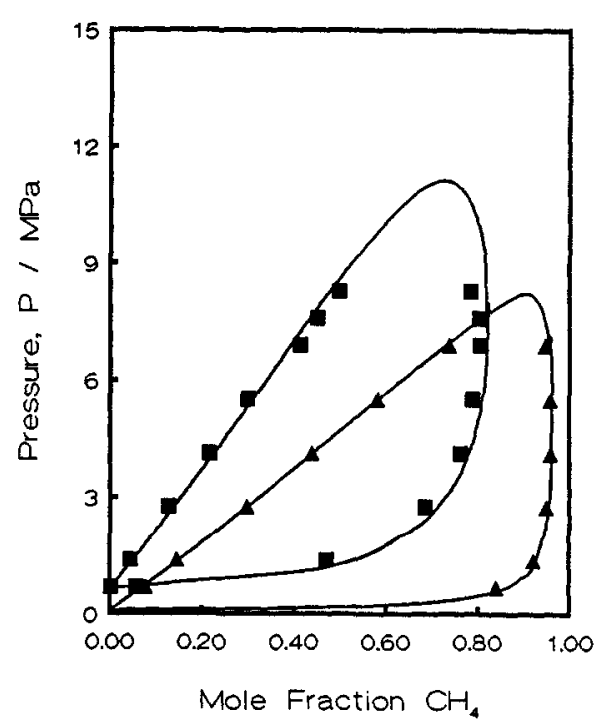

Fig. 3. Phase equilibrium of $\mathrm{CH}_{4}+\mathrm{C}_{3} \mathrm{H}_{8}$ mixtures.

Experiment: $₫ 227.6 \mathrm{~K} ; \backsim 283 \mathrm{~K}$.

Prediction:

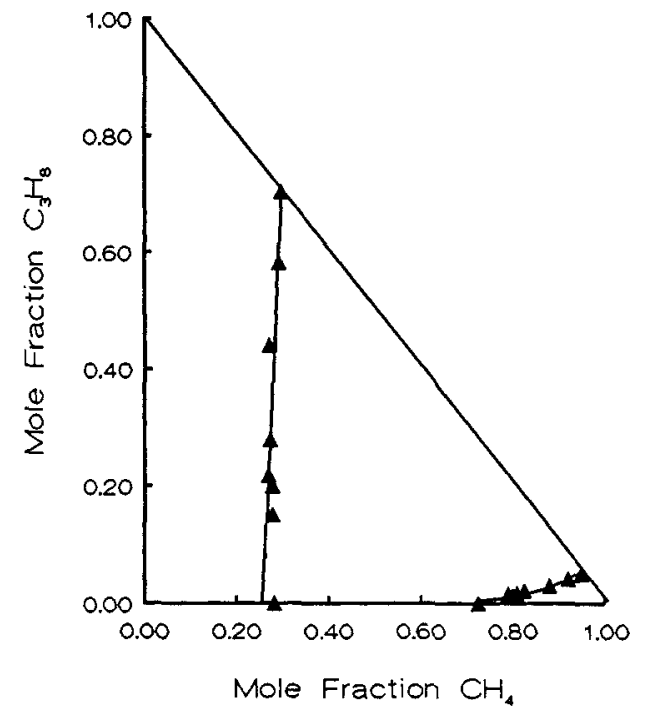

Fig. 4. Phase equilibrium of $\mathrm{CH}_{4}+\mathrm{C}_{2} \mathrm{H}$ $+\mathrm{C}_{3} \mathrm{H}_{8}$ mixtures.

1 Experiment at $227.6 \mathrm{~K}$ and $27.58 \mathrm{kPa}$.

Prediction:

Figure 1 contains the phase envelope for the system nitrogen-carbon dioxide at two different temperatures. For both nitrogen (ref. 12) and carbon dioxide (ref. 13) IUPAC equations of state are available. The experimental data (ref. 14-16) are represented by the symbols and the results of calculations with the Soave-Redlich-Kwong (SRK) model are also shown for the purposes of comparison. It can be seen that the multiple-reference fluid corresponding states approach yields significantly better agreement with experiment over the entire diagram than does the SRK model. Figure 2 contains a similar comparison for the bubble point line of dry air. The comparison with the SRK method is omitted for clarity. The agreement of the predictions of the present procedure with the experimental data (ref. 17) is again good over most of the phase diagram. Figure 3 provides a comparison between the predictions for a binary mxiture of methane and propane and the available experimental data at two temperatures (ref. 18). The good agreement displayed is typical of that over a wider range of conditions for a number of binary mixtures of components whose size ratio is not too different from unity. Finally, Fig. 4 illustrates the behaviour of a ternary system consisting of methane, ethane and propane which might be considered typical of a natural gas. The triangular diagram illustrates that the predictive procedure represents the experimental data (ref. 19) without a great loss of accuracy compared with that achieved for a binary mixture.

\section{TRANSPORT PROPERTIES}

The rigorous theory of the transport properties of dilute gases is formally well developed. However, at elevated densities, the theory is limited by difficulties of a fundamental nature. As a consequence, the development of representations of the properties of even pure fluids over a wide range of thermodynamic states has to be performed empirically with guidance from theories with simple models of the dense fluid state. The starting point is always the separation of contributions from different density regimes. Thus, a transport property $X$ is written

$$
X(\rho, T)=X(0, T)+\Delta X(\rho, T)+\Delta_{C} X(\rho, T)
$$

Here $X(0, T)$ represents the property in the limit of zero-density; $\Delta X(\rho, T)$ the 'excess-property' and $\Delta_{C} X(\rho, T)$ the enhancement of the property in the region around the critical point induced by long-range correlations. For $X(0, T)$ and $\Delta_{c} X(\rho, T)$ there is a considerable amount of useful theory which can be used to correlate and extend available experimental information (ref. 20). For $\Delta X(\rho, T)$ there is less satisfactory theory but a large body of empirical evidence which suggests that at least for a supercritical fluid,

$$
\Delta \mathrm{X}(\rho, \mathrm{T}) \equiv \Delta \mathrm{X}(\rho)
$$


only, so that it is still possible to make use of information over a limited range of temperature to make predictions of the property over a wider range of conditions (ref. 20).

In the case of mixtures the theory is even less well developed for the dense fluid because the enhancement of properties in the critical region has not yet been satisfactorily treated. However, provided that this region is excluded, a viable method of evaluation for the transport properties of mixtures is available that has points of similarity with the treatment of thermodynamic properties outlined above. This is because the procedure can make use of accurate representations of the pure component properties and provide an interpolation between them. The difference is that in the case of the transport properties the interpolation equation is derived for a simple molecular model and is explicit. It is therefore natural to make use of the accurate representation of the transport properties of pure components developed at the Project Centre in London and elsewhere (ref. 20-24) for the prediction of the properties of mixtures. In what follows attention is confined to the viscosity of fluids because it is somewhat simpler algebraically and because the argument for thermal conductivity is essentially the same (ref. 25).

\section{Theory}

For a rigid-sphere model of $\mathrm{N}$ molecular species in a mixture the viscosity at a molar density $\rho$ may be written (ref. 26)

$$
\eta(\rho, \mathrm{T})=-\left[\begin{array}{cccc}
\mathrm{H}_{11} & \cdots & \mathrm{H}_{1 \mathrm{~N}} & \mathrm{Y}_{1} \\
\vdots & & & \vdots \\
\mathrm{H}_{\mathrm{N} 1} & \cdots & \mathrm{H}_{\mathrm{NN}} & \mathrm{Y}_{\mathrm{N}} \\
\mathrm{Y}_{1} & \cdots & \mathrm{Y}_{\mathrm{N}} & 0
\end{array}\right] /\left[\begin{array}{ccc}
\mathrm{H}_{11} & \cdots & \mathrm{H}_{1 \mathrm{~N}} \\
\vdots & & \vdots \\
\mathrm{H}_{\mathrm{N} 1} & \cdots & \mathrm{H}_{\mathrm{NN}}
\end{array}\right]+\kappa_{\operatorname{mix}}
$$

where

$$
\begin{aligned}
& Y_{i}=x_{i}\left[1+\sum_{j=1}^{N} \frac{m_{j}}{\left(m_{i}+m_{j}\right)} x_{j} \alpha_{i j} \bar{x}_{i j} \rho\right] \\
& H_{i i}=\frac{x_{1}^{2} \bar{x}_{i i}}{\eta_{i}^{0}}+\sum_{\substack{j=1 \\
j \neq i}}^{N} \frac{x_{i} x_{j} \bar{x}_{i j}}{2 \eta_{1 j}^{0} A_{i j}^{*}} \frac{m_{i} m_{j}}{\left(m_{i}+m_{j}\right)^{2}}\left[\frac{20}{3}+\frac{4 m_{j}}{m_{i}} A_{i j}^{*}\right] \\
& H_{i j}(j \neq 1)=\frac{x_{i} x_{j} \bar{x}_{i j}}{2 \eta_{i j}^{0} A_{i j}^{*}} \frac{m_{i} m_{j}}{\left(m_{i}+m_{j}\right)^{2}} \times\left[\frac{20}{3}-4 A_{i j}^{*}\right] \\
& K_{m i x}=\left[\frac{16}{5 \pi}\right]\left[\frac{15}{16}\right] \rho^{2} \sum_{j=1}^{N} \sum_{i=1}^{N} x_{i} x_{j} \bar{x}_{i j} \alpha_{1 j}^{2} \eta_{i j}^{0}
\end{aligned}
$$

In these equations $x_{i}$ is the mole fraction of species $i, m_{i}$ its molecular mass and $A_{i j}^{*}$ is a weak functional of the intermolecular pair potential for the $i-j$ interaction readily evaluated from a corresponding states principle (ref. 27). The symbol $\eta_{1}^{0}$ represents the viscosity of pure component $i$ in the low-density limit and $\eta_{1 j}$ the corresponding quantity for the unlike interaction, both of which may be deduced from appropriate experiments on low-density systems or for the corresponding states principle.

The two remaining quantities in equations (13) to (17), related to the effects of density on the transport properties, are $\alpha_{i j}$ which accounts for the shortening of the mean-free path of the gas molecules for an $i-j$ collision at high density and $\bar{\gamma}_{i j}$ which is termed the pseudoradial distribution function for molecules $i$ and $j$ in the mixture. In the case of a mixture of rigid spherical molecules, $\bar{\chi}_{i j}$ coincides with the radial distribution of the hard spheres at contact. However, for a real gas such an interpretation is not possible. Thus, the connection between real systems and the rigid-sphere model is established by allowing $\alpha_{i j}$ and $\bar{\chi}_{i j}$ to be interpreted more loosely - the former to be derived from a mixing rule for hard spheres

$$
\alpha_{i j}=\frac{1}{8}\left[{ }^{1 / 3}{ }^{1 / 3}+\alpha_{j j}^{1 / 3}\right]^{3}
$$

where $\alpha_{i i}$ is to be determined from the properties of the pure gas $i$. The pseudo-radial 
functions $\bar{\chi}_{i j}$ in the mixture are also to be derived from those of the pure gases using a mixing rule based on the Percus-Yevick equation for the radial distribution of hard spheres (ref. 28)

$$
\bar{\chi}_{\mathrm{ij}}(\rho, \mathrm{T})=1+\frac{2}{5} \sum_{\mathrm{k}=1}^{N} \mathrm{x}_{\mathrm{k}}\left(\bar{\chi}_{\mathrm{k}}-1\right)+\frac{\left[\frac{6}{5}\left(\bar{\chi}_{\mathrm{i}}-1\right)^{1 / 3}\left(\bar{\chi}_{\mathrm{j}}-1\right)^{1 / 3} \sum_{\mathrm{k}=1}^{N} \mathrm{x}_{\mathrm{k}}\left(\bar{\chi}_{\mathrm{k}}-1\right)^{2 / 3}\right]}{\left(\bar{\chi}_{\mathrm{i}}-1\right)^{1 / 3}+\left(\bar{\chi}_{\mathrm{j}}-1\right)^{1 / 3}}
$$

in which again the $\bar{\chi}_{\dot{1}}$ are to be deduced from the properties of the pure components.

Di Pippo et al. (ref. 29) and Vesovic and Wakeham (ref. 26) have shown that it is possible to derive both $\alpha_{i i}$ and $\bar{\chi}_{i}$ for the viscosity of a pure component in a totally consistent manner by making use of equation (9) written for a pure component and in the form

$$
\bar{\chi}_{\mathrm{i}}^{ \pm}(\rho, \mathrm{T})=\frac{\beta}{2} \frac{\left(\eta_{\mathrm{i}}(\rho, \mathrm{T})-\rho \alpha_{\mathrm{i} i} \eta_{1}^{0}\right)}{\rho^{2} \alpha_{\mathrm{i}}^{2} \eta_{1}^{0}} \pm \beta\left[\left[\frac{\eta_{\mathrm{i}}-\rho \alpha_{\mathrm{ii}} \eta_{1}^{0}}{2 \rho^{2} \alpha_{i \mathrm{i}}^{2} \eta_{1}^{0}}\right]^{2}-\frac{1}{\beta \rho^{2} \alpha_{i \mathrm{i}}^{2}}\right]^{\frac{1}{2}}
$$

where

$$
\beta=0.8299
$$

According to the procedure of Sandler and Fiszdon (ref. $26 \& 30$ ) the negative root in equation (16) should be applied at low density and the positive root at high density with a changeover at a density, $\rho^{*}$, chosen such that

$$
\frac{\eta_{\mathrm{i}}\left(\rho^{*}, \mathrm{~T}\right)}{\eta_{\mathrm{i}}^{0} \alpha_{\mathrm{i} \mathrm{i}} \rho^{*}}=\frac{2}{\sqrt{\beta}}+1=3.1954 \text { and so that } \bar{\chi}_{\mathrm{i}}^{+}\left(\rho^{*}, \mathrm{~T}\right)=\bar{\chi}_{\mathrm{i}}^{-}\left(\rho^{*}, \mathrm{~T}\right)
$$

This set of conditions determines $\bar{\chi}_{\mathrm{i}}(\rho, \mathrm{T})$ and $\alpha_{\mathrm{ii}}$ uniquely for each isotherm.

The procedure evidently implies that to evaluate the viscosity of a mixture at a particular pressure and temperature, the density of the mixture is required as well as the properties of the pure components and the same molar density and temperature. The methodology outlined in the section on thermodynamic properties makes this possible. Some components may not exist at the molar density of interest at the prescribed temperature but Vesovic and Wakeham (ref. 26) have provided a means of dealing with such cases.

\section{Transport property results}

Figures 5-8 contain the results of the implementation of the calculation procedure described above applied to a number of representative systems. Figure 5 shows a plot of the deviations of the 'experimental' values of the viscosity of dry air, correlated by Kadaya $e t$ al. (ref. 31) from the present predictions. In this calculation air has been treated as a three-component system of $\mathrm{N}_{2}, \mathrm{O}_{2}$ and $\mathrm{Ar}$. Pure component viscosities have been taken from the work of Hanley and collaborators (ref. $21 \& 22$ ). The conditions depicted in the figure cover the temperature range 100 to $500 \mathrm{~K}$ at pressures up to $100 \mathrm{MPa}$. It can be seen that the agreement is generally within $\pm 2 \%$, which is the estimated accuracy of much of the experimental data.

Figure 6 shows the results of the calculation for a ternary mixture of $\mathrm{CH}_{4}-\mathrm{H}_{2}-\mathrm{N}_{2}$ at two temperatures for pressures up to $80 \mathrm{MPa}$, together with the available experimental data (ref. $32)$. Once again the discrepancies are of the order of $2 \%$. The viscosity of pure hydrogen has been taken from the work of Assael et al. (ref. 33) and McCarty et al. (ref. 34), while that for methane has been taken from the work of llanley et al. (ref. 23). Figure 7 illustrates the results for the methane-propane system at $311 \mathrm{~K}$ for three isopleths over a range of conditions which encompass both the gaseous and liquid states. Here the viscosity of pure propane has been taken from the work of llolland et al. (ref. 24). In the gas phase the agreement between prediction and experiment is typically within $\pm 1 \%$, whereas in the liquid phase the discrepancy rises to $\pm 6 \%$. Finally, Fig. 8 shows the results of the corresponding calculation for the thermal conductivity of air in the temperature range 200-500 K at pressures up to $100 \mathrm{MPa}$. the details are given in full elsewhere (ref. 25). The agreement of the calculations with the 'experimental' data (ref. 31 ) is within $\pm 2 \%$ even though no data on the behaviour of the thermal conductivity at elevated densities have been included. 


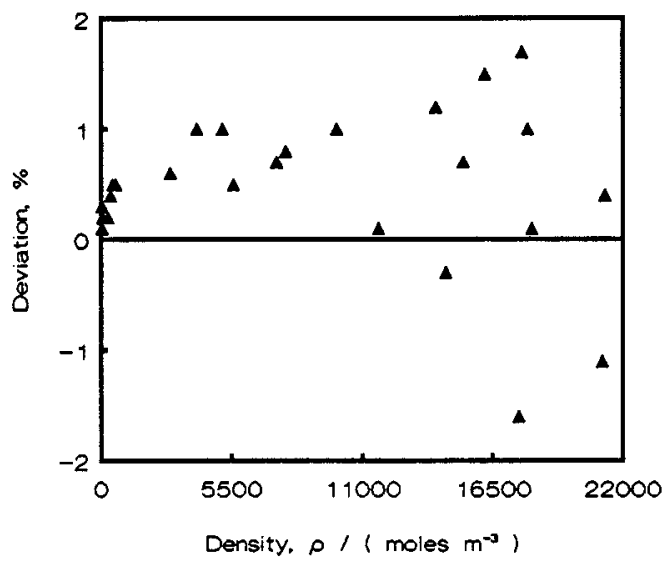

Fig. 5. Deviations of experimental data for the viscosity of air from the predictions.

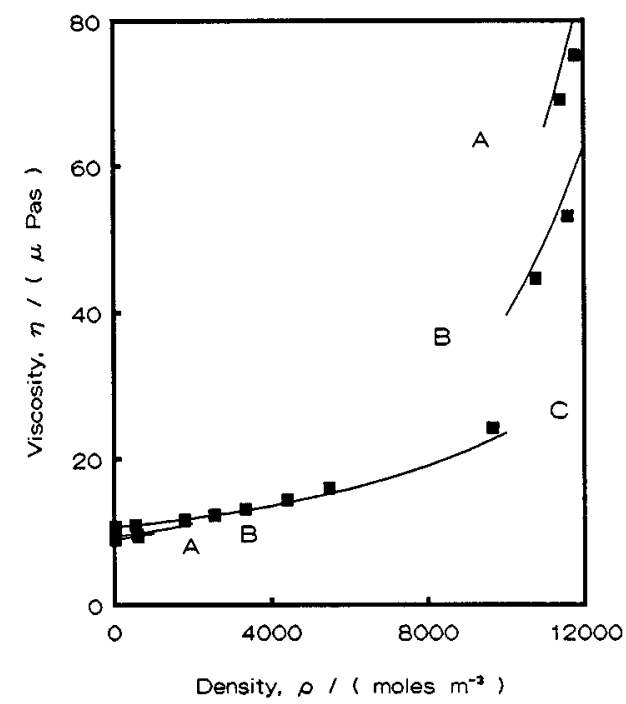

Fig. 7. Viscosity of $\mathrm{CH}_{4}+\mathrm{C}_{3} \mathrm{H}_{8}$ mixtures at $311 \mathrm{~K}$.

$\mathrm{A}: \mathrm{x}_{\mathrm{CH}_{4}}=0.22 ; \mathrm{B}: \mathrm{x}_{\mathrm{CH}_{4}}=0.39 ; \mathrm{C}: \mathrm{x}_{\mathrm{CH}_{4}}=0.79$.

Experiment: ; calculation: -

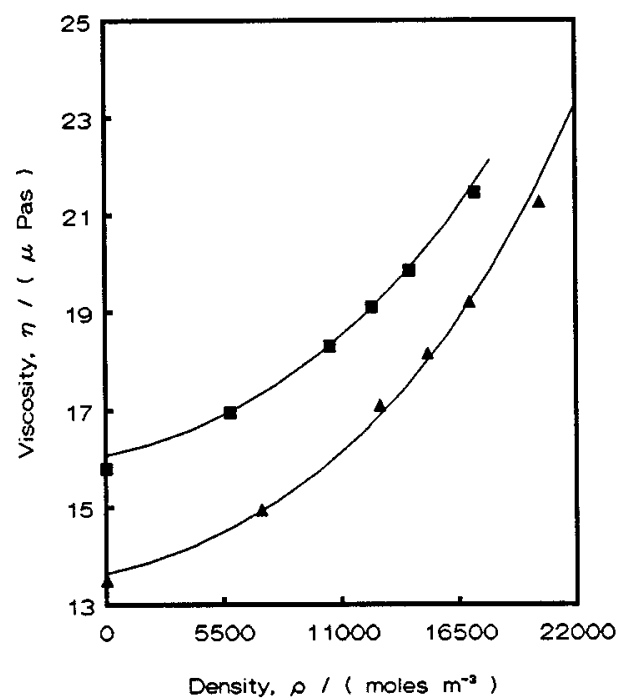

Fig. 6. Viscosity of a $\mathrm{CH}_{4}-\mathrm{H}_{2}-\mathrm{N}_{2}$ mixture $\left(\mathrm{x}_{\mathrm{CH}_{4}}=0.17, \mathrm{x}_{\mathrm{H}_{2}}=0.625\right)$.

॥: $\mathrm{T}=298 \mathrm{~K} ; \mathbf{\mathrm { v }}: \mathrm{T}=373 \mathrm{~K} ;$ - calculation

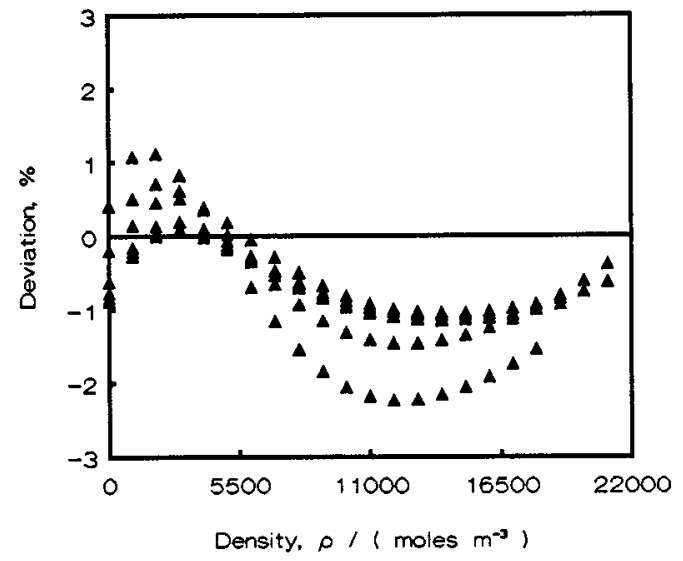

Fig. 8. Deviations of experimental data for the thermal conductivity of air from the predictions.

\section{SOFTWARE}

The two predictive methods described above make use of accurate representations of the thermophysical properties of the pure components and a separate pair of parameters characteristic of each binary interaction for the thermodynamic and transport properties. All of the calculations presented here were performed with a computer package which will form a part of the revised computer database issued by the Physical Properties Data Service with the UK National Engineering Laboratory. It should be clear from the methodology described that as accurate representations of the pure components are developed at the Project Centres in London and elsewhere, so it becomes possible to expand the number of mixtures treated in a factorial fashion. 


\section{Acknowledgements}

The author is indebted to Dr. V. Vesovic and $\mathrm{Mr}$. S.B. Cha for their contributions to this paper and to many members of the IUPAC Subcommittee on Transport Properties for stimulating discussions. Financial support for the IUPAC Centres is provided by the UK Department of Trade and Industry.

\section{REFERENCES}

1. S. Angus, K.M. de Reuck and B.J. Armstrong, International Tables of the Fluid State8: Chlorine, Pergamon Press, Oxford (1985).

2. R.T. Jackson, M. Jahangiri, R.B. Stewart, R.D. McCarty, J.M.H. Levelt-Sengers, H.J. White Jr., J.V. Sengers and G.A. Olchowy, International Thermodvnamic Tables of the Fluid State - 10: Ethvlene, (Eds. K.M. de Reuck, S. Angus, W.A. Cole, R.J.B. Craven and W.A. Wakeham), Blackwell Scientific Publications, Oxford (1988).

3. I.D. Watson and J.S. Rowlinson, Chem. Engng. Sci. 24, 1565-1575 (1969).

4. I.D. Watson and J.S. Rowlinson, Chem. Engng. Sci. 24, 1575-1580 (1969).

5. G.A. Mansoori, Mixing Rules for Cubic Equation of State, Equations of State: Theories and Applications, K.C. Chao, R.L. Robinson, Ed., pp. 314-331, A.C.S., Washington D.C., $(1986)$.

6. T.W. Leland, P.S. Chappelear and B.W. Gamson, AIChE J. 8, 482-489 (1962).

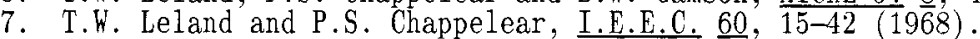

8. T.W. Leland, J.S. Rowlinson, G.A. Sather and I.D. Watson, Trans. Faraday Soc. 64, 2034-2043 (1968).

9. S.B. Cha, PhD Thesis, Imperial College (1990).

10. J.W. Leach, P.S. Chappelear and T.W. Leland, AIChE J. 14, 568-576 (1968).

11. D. Essien, S.B. Cha and H.A. Wakeham, Proc. 2nd Asian Thermophysical Properties Conference, p. 399, Japanese Society for Thermophysical Properties, Tokyo, (1989).

12. S. Angus, K.M. de Reuck and B. Armstrong, International Thermodynamic Tables of the Fluid State - 6: Nitrogen, Pergamon Press, Oxford (1979).

13. S. Angus, K.M. de Reuck and B. Armstrong, International Thermodynamic Tables of the Fluid State - 3: Carbon Dioxide, Pergamon Press, 0xford (1976).

14. Y. Arai, G. Kminishi and S. Saito, J. Chem. Engng. Japan 4, 113-121 (1971).

15. F. Somait and A.J. Kidnay, J. Chem. Engng. Data 23, 301-308 (1978).

16. T. Al-Sahhaf, A.J. Kidnay and E.D. Sloan, Ind Engng. Chem. Fund. 22, 372-379 (1983).

17. J.C. Rainwater and R.J. Jacobsen, Cryogenics 28, 22-32 (1988).

18. R. Kobayashi and A.R. Price, J. Chem. Eng. Da.ta 4, 40-52 (1959)

19. J.M. Bendoin, and J.P. Kohn, J. Chem. Eng. Data 12,1840191 (1967).

20. V. Vesovic, W.A. Wakeham, G.A. 01chowy, J.V. Sengers, J.T.R. Watson and J. Millat, J. Phys. Chem. Ref. Data (in press).

21. H.J.M. Hanley, R.D. McCarty and H.M. Ilaynes, J. Phvs. Chem. Ref. Data 3, 979-1017 (1974).

22. B.A. Younglove and II.J.M. Hanley, J. Phys. Chem. Ref. Data 15, 1323-1337 (1986).

23. H.J.M. Hanley, W.M. Haynes and R.D. McCarty, J. Phys. Chem. Ref. Data 6, $597-609$ (1977) .

24. A.M. Holland, H.J.M. Hanley, K.E. Gubbins and J.M. Ilaile, J. Phys. Chem. Ref. Dava 8 , $559-575$ (1979).

25. V. Vesovic and H.A. Wakeham (in preparation).

26. V. Vesovic and W.A. Hakeham, Chem. Engng. Sci. 44, 2181-2189 (1989)

27. G.C. Maitland, E.B. Smith, M. Rigby and W.A. Hakeham, Intermolecular Forces, pp. 564-567, Clarendon Press, 0xford (1981).

28. T.M. Reed an K.E. Gubbins, Applied Statistical Mechanics, Chapter 9, McGraw-Hill, New York (1973).

29. R. Di Pippo, J.R. Dorfman, J. Kestin, H.E. Khalifa and E.A. Mason, Physica 86A, 205-223 (1977)

30. S.I. Sandler and J.K. Fiszdon, Physica 9.5A, 602-608 (1979).

31. K. Kadaya, M. Matsunaga and A. Nagashima, J. Phvs. Chem. Ref. Data 14, 947-970 (1985).

32. I.F. Golubev, Viscositv of Gases and Gas Mixtures, p. 212, Israel Program for Scientific Translation, Jerusalem (1970).

33. M.J. Assael, S. Mixafendi and W.A. Wakeham, J. Phys. Chem. Ref. Data 15, 1315-1322 (1986).

34. R.D. McCarty, J. Hard and II.M. Roder, Selected Properties of Hydrogen, NBS Monograph, No. 168, U.S. Department of Commerce (1981). 